\title{
Psychiatry in Libya: eastern region
}

\author{
Selim M. El-Badri
}

Lbya occupies an approximate area of 1.8 million sq. $\mathrm{km}$ in the northern part of Africa, with a population of 4.5 million. Of the population, 97\% are Muslims, $46.5 \%$ are under 15 years and only $2.3 \%$ are over 65 years of age. Stxty-four per cent of the population live in urban areas and the literacy rate is $60 \%$. Tripoli, situated in the west, is the capital city of Libya and Benghazi, the second biggest city, is situated in the east of the country and the distance between the two citles is about $1000 \mathrm{~km}$. The population of Benghazt and eastern Lbya is about 2 million.

The first sanatorium for mental disorders in eastern Libya was established in 1950 at AlMarj Khadim, a small town situated $100 \mathrm{~km}$ from Benghazd, under the supervision of one foreign doctor and a small number of unqualified nurses.

In the year 1963 the Al-Marj town was demolished in a severe earthquake and as a result, the majority of patients were transferred to Tripoll Psychiatric Hospital and a small number of patients were moved to the Central Hospital in Benghazd. The Central Hospital's psychiatric ward, staffed by two foreign doctors and a number of Arab nurses, treated the patients for 11 years with limited facilities. It is worth mentioning that traditional faith healers also take an active role in the management of mentally ill people in Libya, probably up to the present time. In 1974, the first specifically psychiatric hospital was built in the village of 'Gwarsha' about $15 \mathrm{~km}$ west of Benghazi, with 200 beds and was named 'Dar Al-Shafa'. In the beginning, due to a shortage of trained personnel as well as the stigma associated with mental illness, admission to hospital was considered a social disgrace. It was not until 1980 that a serious attempt was made to provide modern facilities for the psychiatrically 111 .

The site chosen for the new hospital was one of the suburbs of Benghazd (Hawari), where the Medical School, Children's Hospital and the main teaching hospital are situated. The hospital with 200 beds was completed and opened in 1982 and this gave psychiatry a new look and status in Benghazd.

While the old psychiatric hospital at Gwarsha was isolated, the new psychiatric hospital was located close to all the other hospitals. However, the old Gwarsha hospital was kept for 125 long-stay psychiatric patients. In the new hospital there is a Department of Clinical Psychology, a Department of Neurophysiology (EEG) and also a Department of Psychiatric Social Services. The hospital has its own X-ray, ECG and basic laboratory facilities. The hospital provides services for the whole of eastern Libya, particularly for the nonresponders to out-patient treatment in other centres in eastern Libya, and those who need in-patient care. There are also ancillary services that are provided at the El Keish polyclinic which is situated in the city centre. Out-patient clinics are held four full days a week (a full day of working is from 8.00 am to $2.00 \mathrm{pm}$ ) run by one of the specialists in psychiatry with the help of two junior doctors each day. The average number of out-patients is about $\mathbf{5 0}$ daily of whom about ten are new patients. There are also satellite clinics and depot injection clinics in the periphery of the region. Besides the out-patient facilities at the polyclinic the psychiatric hospital provides a 24 hour service for emergency cases. This provides a crisis intervention service and offers an alternattve to hospital admission. There are no in-patient facilities for psychiatrically ill children. However, out-patient services for children are provided once a week at the Children's Hospital.

The community services are still not well developed but serlous efforts are being made to provide a consultation service to geriatric homes, child welfare centres and for the mentally retarded in special schools.

Specialised forensic services or units do not exist but the hospital doctors in charge of the Medical Board provide similar services. A Medical Board comprising the medical director of the hospital (Benghazd Psychiatric 


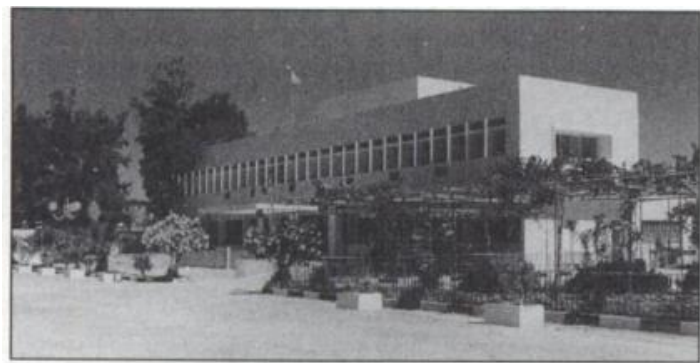

Benghazl Psychlattic Hospltal

Hospital), a consultant psychiatrist and a junior hospital doctor, usually a registrar, is responsible for medico-legal matters. At the request of the Courts they examine prisoners and subsequently submit reports to the Courts. This board is appointed by the Medical Director. There is no Mental Health Act and what happens in practice is usually dictated by the family's wishes. For example, a family member, usually next of kin, can ask for his relattve to be admitted to hospital compulsorily. This has the same force as a section of the Mental Health Act in the UK.

The patient is usually discharged to his next of kin and if the next of kin refuses to take the patient after several requests, the patient can either be discharged or taken to his place of residence. The next of kin can also discharge a psychiatrically ill patient against medical advice. Most of the acute wards are locked. There is, however, one ward which is open and usually kept for more manageable and less acutely ill patients

Treatment involves the use of various neuroleptics, ant1-depressants and electroconvulstve therapy (ECT). ECT is usually given by the consultant staff in contrast to the practice in the Republic of Ireland and the UK. Other treatment options such as psychotherapy, cognittive and behavioural approaches are very under-used due to a shortage of specialised and trained staff.

The Benghard Psychiatric Hospital is a teaching hospital affliated to Al-Arab Medical Untversity. Third year undergraduate students attend psychiatric teaching programmes. Lectures are given by spectalists once a week at the Untversity and cover the whole fleld of psychiatry. Medical students in groups of eight to 12 spend a month at the hospital, study psychiatric cases and present them for discussion. Examinations are held at the end of each month and the marks and attendance count for the final examinations. All medical students are fluent in English and all lectures and examinations are in English. Psychitatry is not popular among medical students and very few young local doctors work in psychiatry.

In order to provide a comprehenstve training programme, distinguished psychiatrists and professors are invited from Europe and other countries in special fields of psychiatry for two to four weeks to provide supplementary sessions for the under-graduate and also to give post-graduate lectures to the doctors in general medicine.

In order to improve primary health care, a basic course in psychiatry was held in December 1985 at the new Psychiatric Hospital, where a large number of general practitioners and medical officers from all over Libya were given a special seminar lasting a week. The seminar was successful and there is a demand for more meetings like this in the future. There is not yet a Department of Psychlatry, and psychiatry is still under the Department of Medicine but the Untversity provides the hospital with well qualified academic teaching staff. A new Untversity Hospital with a capacity of 1200 beds is under construction in Benghazt with a 50 bed psychiatric wing. The mult-purpose primary health centres, 'polyclinics', which are already in operation will need to be further developed to provide primary health services in the fleld of prophylactic and therapeutic psychiatric medicine.

In conclusion, the mental health services of the eastern region of Llbya are developing slowly but in the right direction and are following the guidelines of the World Health Organization recommendations and also of the scientific panel of the Organization of African Unity in 1975.

Selim M. El-Badri, Registrar in Psychiatry, Department of Psychiatry, Regional Hospital, Dooradoyle, Limerick, Republic of Ireland 